\title{
IMPLEMENTATION OF RAINWATER IN PREPARATORY PROCESSES AS WELL AS DYEING OF KNITTED COTTON FABRIC AND COMPARE THE EFFECTS WITH GROUND WATER
}

\author{
Md. Samiul Alom, Farjana Badhon and Shompa Rani Halder \\ National Institute of Textile Engineering \& Research (NITER), Savar, Dhaka 1350 \\ Tonmoy Saha* \\ Bangladesh University of Textiles, Tejgaon Industrial Area, Dhaka-1208
}

\begin{abstract}
Textile industries are very much intensive to water. A large amount of water is consumed every day during various textile processes and one of the main sources of this water is groundwater. This project aimed to work with rainwater which can be an alternative source of groundwater. In this project, the quality of rainwater was evaluated first and matched with the standard. From different tests such as turbidity, water hardness, amount of dissolved solids, and iron content, we found that the rainwater achieved the standard level of dye house water supply. After that, different wet preparatory processes, as well as dyeing of cotton fabric were carried out using rainwater. After completion of each process, evaluation was carried out such as weight loss percentage and absorbency for scouring, whiteness index for bleaching, and colour fastness tests of dyed fabric. The results were excellent compared with conventionally groundwater treated fabric.
\end{abstract}

Keywords: Water consumption, Rainwater, Ground water, Pretreamtent, Dyeing

\section{Introduction}

Textile industries is considered as one of the anthropogenic activities as well as oldest sectors which mainly comprised of different complex processes [1]. To carry out these complex processes, different types of utilities as well as raw materials are used and ground water is one of the most substantive elements for textile production processes [2]. Textile industries put an excess strain on the global water resource because in textile, most of the processes in textile manufacturing requires considerable amount of water [3]. A good illustration of this can be seen in an average textile composite factory which manufactures $8000 \mathrm{~kg}$ fabric/day and consequently consumes about 1.6 million liters water/day [4]. Mechanical processing of textiles such as spinning, weaving requires less water. However, the major processes in chemical processing including pretreatment, dyeing, printing and finishing use ground or surface water as their primary segment to apply different types of dyes and chemicals on to the materials [5]. Water primarily applied in pretreatment followed by dyeing and finishing [6]. Among of these processes, only aqueous dyeing requires around 100-180-liter water to dye $1 \mathrm{~kg}$ fabric [7]. Dyeing of cotton fabric with reactive dyes consumes a significant amount of water which is detrimental to the environment [8]. Moreover, after treatment process of reactive dyeing also requires a lot of water to remove residual alkali. Apart from that, boiler, ion-exchange, cooling system and steam drying process also requires water. Again, water consumption varies widely depending upon the type of textile fiber and the form possessed, applied methods, equipment and characteristics [9]. As a consequence, water available in the earth is decreasing continuously and it has become a global concern because if this situation is allowed to continue, a tipping point will be reached where severe water crisis will happen [10]. So, the alternative of using ground water is the biggest concern to keep sustainability in textiles processing. There are numerous studies carried out to combat this crisis and reduce water footprint substantially. In this case, solvent assisted dyeing approach has made significant progress in recent times. For example, ethanol (EtOH)-carbon tetrachloride $\left(\mathrm{CCl}_{4}\right)$-water $\left(\mathrm{H}_{2} \mathrm{O}\right)$ solvent-assisted dyeing system was proposed for the reactive dyeing of cotton. [11]. Again, other studies investigated PEG-based solvent-assisted reverse micelle dyeing system to reduce water consumption [12]. Air flow dyeing system is the latest technology available in the market today to 
reduce ground water consumption. [13]. However, this advanced technologies and solvent dyeing system has several limitations such as high installation cost and expensive price of chemicals. This project aimed to use an eco-friendly approach by using rainwater as an alternative of ground water. For this purpose, at first rainwater was collected from different five regions of Bangladesh. After that, different quality parameters of rainwater were assessed. Pre-treatment followed by dyeing was carried out using rainwater as well as ground water and finally compare the effects. From the results, it is coherent that results obtained using rainwater is satisfactory in comparison with the conventional use of ground water.

\section{Materials}

$100 \%$ single jersey grey cotton was used as and the fabric was collected from A.K.H Garments \& Textile Ltd., Rajfulbaria, Savar, and Dhaka. Procion blue $3 \mathrm{X}-2 \mathrm{R}$ reactive dye was used for dyeing cotton fabric. As an electrolyte glauber salt was used and caustic soda was used for fixation. To improve the dyeing properties wetting agent and leveling agent was also used. Dyes and auxiliaries were collected from Mitali Scientific Store, Dhaka. Rainwater was collected in the conventional process through polyethene in the rainy season in the open space from five different regions of Bangladesh, and they are R1: Nayarhat, Savar, Dhaka (23055'1.164" N, 90¹3'55.6896" E); R2: Bandar, Narayangonj (23037'8.67" N, 90'30'51.23" E); R3: Sreepur, Gazipur (24012'0.71' N, 90²8'43.35” E), R4: Char Beutha, Manikganj (23050’31.91' N, 900'2.7” E) (2, and R5: Sujanagar, Rajshahi $\left(24^{\circ} 23^{\prime} 47.15^{\prime \prime} \mathrm{N}\right.$, 88036'17.23”'E).

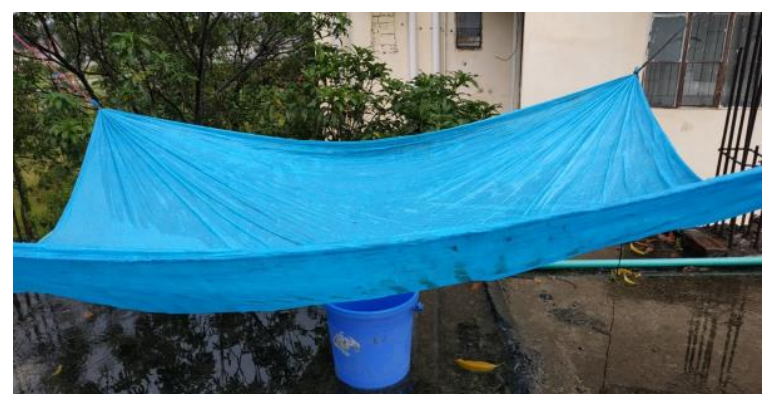

Fig.1: Collection of rainwater

Rainwater was collected from the five months of period of May to September. Heavy rainfall occurred on that particular time, considering the geography of Bangladesh.

Ground water was collected and used from Rajashon, Savar, Dhaka (23050'54.73” N, 90¹6’45.75” E).

\section{Methodology}

\subsection{Water Quality Parameters Test}

At first different standard dye house quality parameters of rainwater were tested. $\mathrm{pH}$ of rainwater was tested by using $\mathrm{pH}$ meter. Hardness of water was estimated using EDTA method. Turbidity of rainwater was evaluated by $\mathrm{HACH}$ method. Iron content percentage was measured by using method. Biological Oxygen Demand (BOD) and Chemical Oxygen Demand (COD) were evaluated using APHA/In House/BOD and APHA/In House/COD respectively. Total Dissolved Solids was measured by APHA/In House/TDS method.

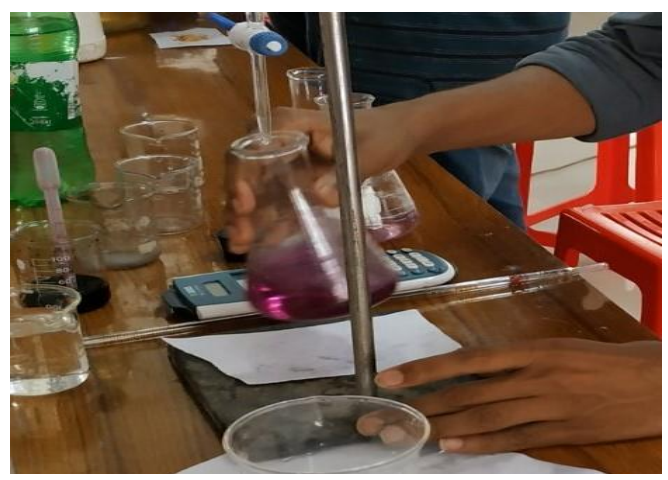

Fig.2: Water Hardness test using EDTA method

\subsection{Combined Scouring-Bleaching process}

Combined scouring-bleaching process was carried out in order to remove impurities and increase the whiteness of the materials.

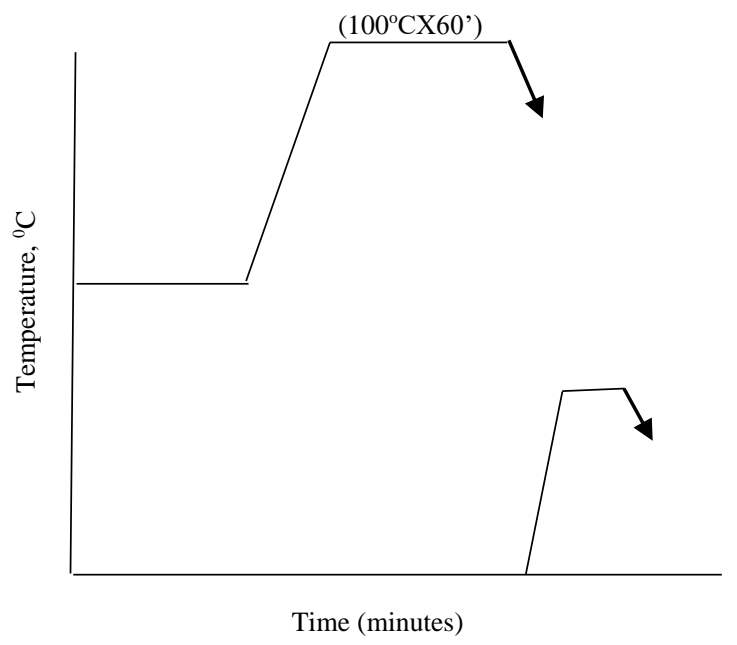

Fig.3: Combined Scouring-Bleaching Process 
Table 1

Following recipe and process had been used for this purpose

\begin{tabular}{|c|c|c|c|}
\hline Auxiliaries & Amount & Auxiliaries & Amount \\
\hline Sodium silicate & $2 \mathrm{~g} / \mathrm{L}$ & Detergent & $2 \mathrm{~g} / \mathrm{L}$ \\
\hline Caustic soda & $5 \mathrm{~g} / \mathrm{L}$ & Sequestering Agent & $1 \mathrm{~g} / \mathrm{L}$ \\
\hline Hydrogen peroxide $(35 \%)$ & $4 \mathrm{~g} / \mathrm{L}$ & Temperature $\times$ Time & $100^{\circ} \mathrm{C} \times 60 \mathrm{mins}$ \\
\hline Wetting agent & $1 \mathrm{~g} / \mathrm{L}$ & M: L & $1: 10$ \\
\hline
\end{tabular}

\subsection{Dyeing of knitted fabric with reactive dye}

After pre-treatment of knitted cotton fabric, dyeing was carried out using rainwater and ground water, reactive dyes (Procion blue 3X-2T) and with the help of salt and soda. Following recipe and process had been used for dyeing:

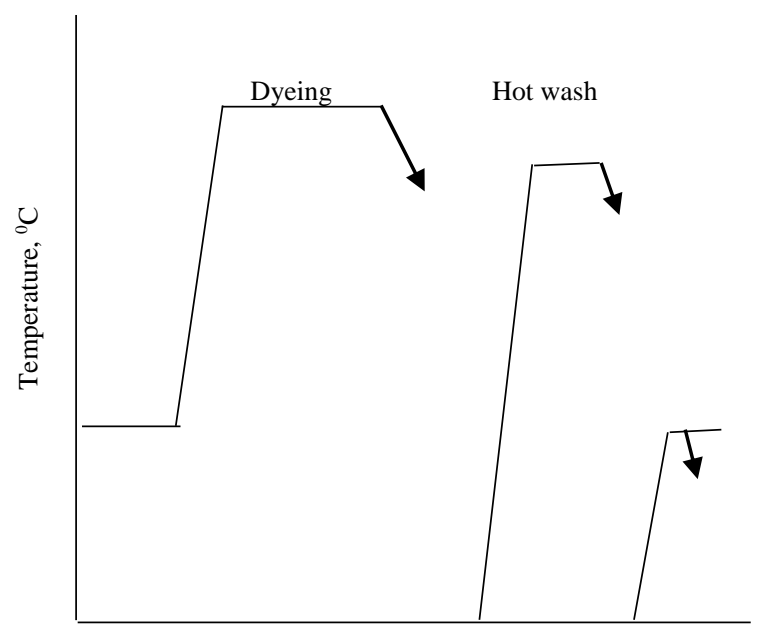

Time (minutes)

Fig.4: Dyeing Process of cotton knitted fabric

\subsection{Colour Fastness Test}

Colour fastness to wash was evaluated by using ISO 105 C06 method. For colour fastness to perspiration and rubbing evaluation, BSENISO-105 E04 and BSENISO-105 X 12 methods were used respectively. Colour fastness to light was assessed by using BSENISO-105-BO2 method. Colour fastness to wash, perspiration and rubbing were evaluated using grey scale rating from 5 being good to 1 being poor. Colour fastness to light was evaluated using blue scale rating. The Blue Wool Scale ranges from 1 (very low colour fastness to light) to 8 (very high colour fastness to light)

\section{Results and Discussion}

\subsection{Rainwater quality parameter analysis}

From Table 3 we can see that different parameters for rainwater match with the standard requirement of dye house water supply. Here, R1, R2, R3, R4, R5 represents different regions from where we collect rainwater and $\mathrm{GW}$ indicates ground water parameter that we use. As we know the quality of dye bath water, no need to do any further treatment with rainwater. All the parameter including $\mathrm{pH}$, water hardness, iron content is in tolerance.

\subsection{Evaluation of combined scouring-bleaching}

Assessment of combined scouring bleaching process was carried out in the form of weight loss percentage test, drop test (absorption time in sec), column wicking test (in $\mathrm{mm}$ ) and whiteness value index. The result of the weight loss percentage for rainwater is more than $0.5 \%$ compared to the ground water and it eventually match the standard weight loss of scouring process that is (4-8\%). Secondly, the absorption time for both rain and ground water treated process match the standard absorption time of scouring.

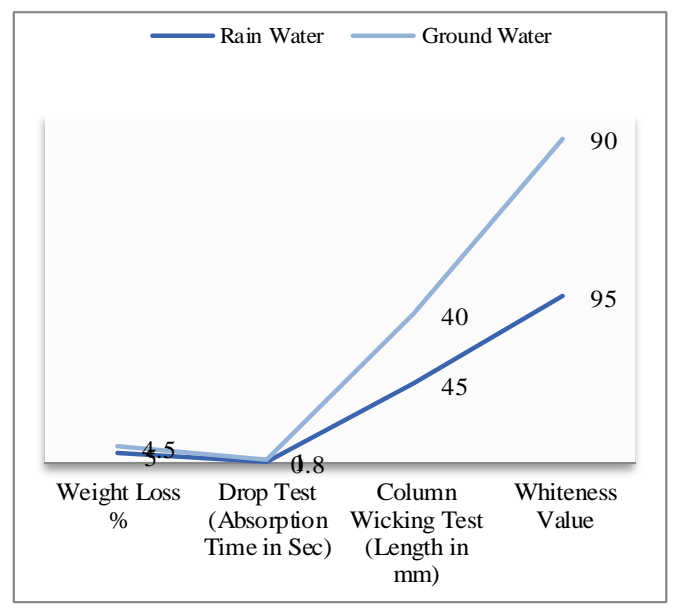

Fig.5: Evaluation of combined scouring-bleaching process 
Table 2

Following recipe and process had been used for dyeing:

\begin{tabular}{llll}
\hline Dyes \& Auxiliaries & Amount & Auxiliaries & Amount \\
\hline Dyes & $1.5 \%$ (owf) & Sequestering Agent & $1 \mathrm{~g} / \mathrm{L}$ \\
Salt & $40 \mathrm{~g} / \mathrm{L}$ & Temperature & $100^{\circ} \mathrm{C}$ \\
Soda & $10 \mathrm{~g} / \mathrm{L}$ & Time & $60 \mathrm{mins}$ \\
Wetting agent & $1 \mathrm{~g} / \mathrm{L}$ & M: $\mathrm{L}$ & $1: 10$ \\
\hline
\end{tabular}

Table 3

Rainwater and ground water quality parameters

\begin{tabular}{|c|c|c|c|c|c|c|c|}
\hline Parameter & Unit & R 1 & R 2 & R 3 & R 4 & R 5 & Ground Water \\
\hline $\mathrm{pH}$ & - & $6.6-7.0$ & $5.8-6.9$ & $6.2-6.9$ & $6.5-6.7$ & $6.5-6.9$ & $7.32-7.82$ \\
\hline TDS & $\mathrm{mg} / \mathrm{L}$ & $26.0-50.7$ & $29.9-46.2$ & $45.3-67.4$ & $13.5-15.6$ & $18.9-38.4$ & $529.32-951.48$ \\
\hline BOD & $\mathrm{mg} / \mathrm{L}$ & $2.2-3.2$ & $2.1-3.1$ & $1.7-3.0$ & $1.7-2.1$ & $1.4-2.1$ & $0.58-0.92$ \\
\hline $\mathrm{COD}$ & $\mathrm{mg} / \mathrm{L}$ & $7.0-33.0$ & $9.0-32.0$ & $8.0-29.0$ & $6.0-35.0$ & $8.0-16.0$ & $76-135$ \\
\hline Turbidity & NTU & $15.0-18.0$ & $11.1-19.2$ & $11.0-18.1$ & $7.7-11.7$ & $8.4-12.1$ & $6-16$ \\
\hline Iron & $\mathrm{ppm}$ & 0.05 & 0.08 & 0.09 & 0.04 & 0.06 & $0.618-0.924$ \\
\hline Hardness & ppm & 31 & 20 & 19 & 23 & 24 & $912-1100$ \\
\hline
\end{tabular}

After that, from the chart we can see that wicking length of absorption is higher when we treated material with rainwater. The absorption length of wicking is $45 \mathrm{~mm}$ compared to the wicking length of ground water treated scoured fabric which is $40 \mathrm{~mm}$. Whiteness value of the rainwater treated fabric is 95 whereas water treated fabric is 90 . Overall, scouringbleaching effect is satisfactory in both cases; rainwater and ground water.

\subsection{Evaluation of Dyeing}

Assessment of dyeing was carried out to evaluate shade and colour difference between two dyed samples. It is observed that shade variation is within acceptable limit between two dyed samples.

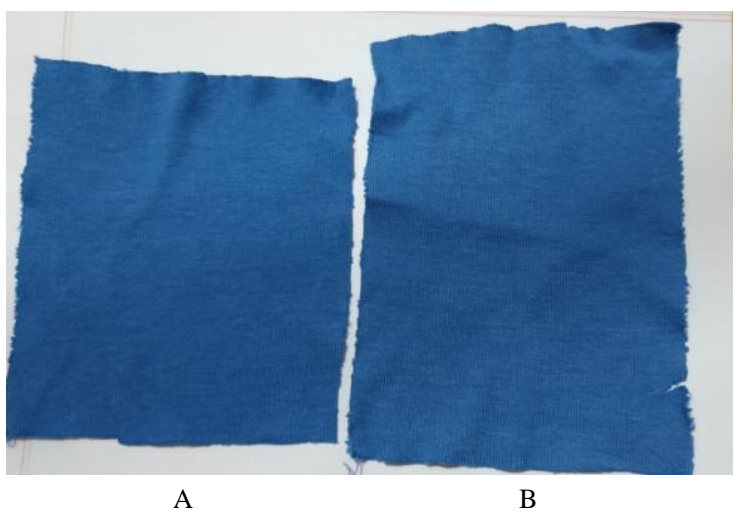

Fig.6: Dyed cotton knitted fabric (A. By using Rainwater, B. By using ground water)

\subsection{Evaluation of colour fastness to light}

From the chart below, we can see that colour fastness to light value for both rainwater and groundwater treated dyed fabric is satisfactory.

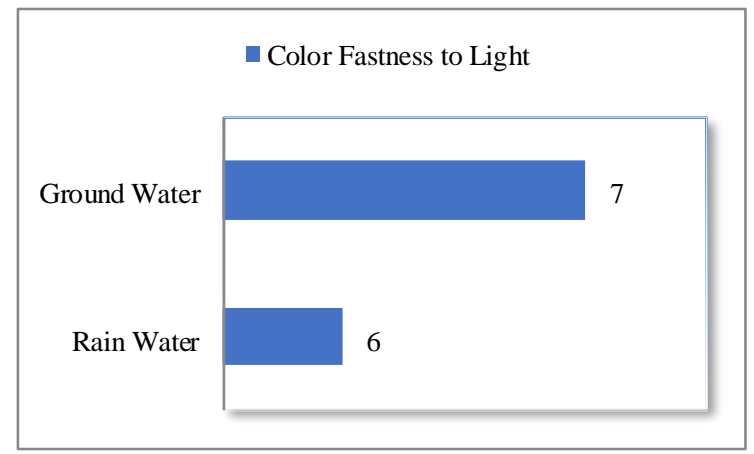

Fig.7: Evaluation of colour fastness to light

\subsection{Evaluation of colour fastness to wash, rubbing and perspiration}

The grey rating scale value for colour fastness to wash is $4 / 5$ for rainwater and 4 for ground water which is satisfactory. Again, grey scale rating for colour fastness to rubbing is 4 for both cases. Grey scale rating for colour fastness to perspiration is respectively $4 / 5$ and 4 for rainwater and ground water dyed fabric. There is no big difference in result of colour fastness between rainwater and ground water treated fabric. 


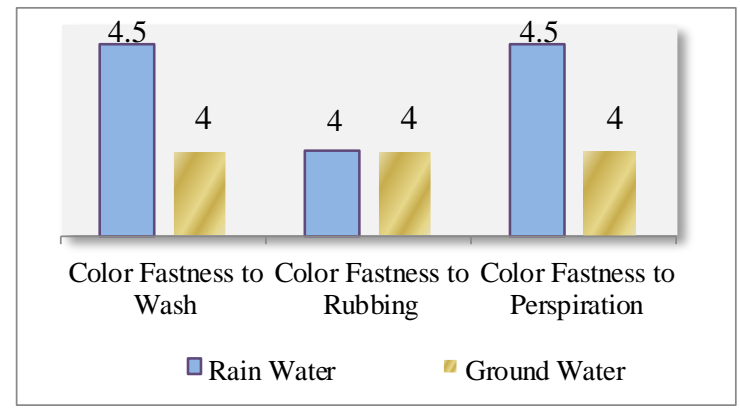

Fig.8: Evaluation of colour fastness to wash, rubbing and perspiration

\subsection{Rainwater harvesting model to reduce water footprint}

To reduce the water footprint, the alternative of using groundwater is the biggest concern to achieve sustainability in the manufacturing process as well as keeping environment free from contaminants. Bangladesh is privileged by a huge quantity of rainwater annually throughout the country and thus, rainwater harvesting can be the most potential alternative water supply for the textile industries. Rainwater harvesting is the accumulation and storage of rainwater for reuse on-site, rather than allowing it to run off. May to September, these five months are the prospects for the rainfall and the expected volume of rainwater in a season is around 5070 cubic meters. Fortunately, these months are pick season for the knitwear production, so the project can be successful and effective if the rainfall happens as per the calculation. Recently, Robintex group has designed a project to collect rainwater by using 15,096 Square Meter rooftop area which consists of three rainwater harvesting tanks [14].

\subsection{Summary of the result}

From the results, it is lucid that rainwater is an effective alternative of ground water considering the shade and fastness properties showed by the rainwater treated dyed fabric. The results of preparatory processes also matched the actual standard when pre- treated fabric with rainwater. The introduction of rainwater in textile dyeing processes has not only achieved quality but also encouraged sustainable practices of textile manufacturing. However, climate conditions are the prerequisite for using rainwater. Effective harvesting of rainwater in a season can collect rainwater and use it later in textile processing. The harvesting method is to store rainwater and makes them ready for the use in mass production. In comparison, ground water requires multiple processes to be purified while rainwater is a cost-effective approach in terms of purification. The harvesting method consents collecting large amount of water which is free from any impurities and can be used directly in different textile processes to reduce time and cost.

\section{Conclusion}

The main aim of the project was to work with rainwater which can be an alternative source of groundwater. In this project, the quality of rainwater was evaluated first and matched with standard form different tests such as turbidity, water hardness, number of dissolved solids, and iron content. We found that rainwater achieved the standard level of dye house water supply. After that different wet preparatory processes, as well as dyeing of cotton fabric, were carried out for each process such as weight loss percentage, absorbency, and whiteness index, and colour fastness. The results were excellent compared with conventionally groundwater treated fabric. The future prospect of the project is to develop a method for harvesting rainwater in different period of time.

\section{Acknowledgement}

Rainwater quality parameters such as Iron content, Turbidity, Biological Oxygen Demand, Chemical Oxygen Demand and Total Dissolved Solid tests were carried out in Bangladesh University of Engineering and Technology (BUET) environmental laboratories. Their support is highly acknowledged.

\section{References}

[1] Yukseler, H.; Uzal, N.; Sahinkaya, E.; Kitis, M.; Dilek, F. B.; Yetis, U. Analysis of the Best Available Techniques for Wastewaters from a Denim Manufacturing Textile Mill.J. Environ. Manage. 2017, 203 (Pt 3), 1118-1125.

[2] GilPavas, E.; Dobrosz-Gómez, I.; Gómez-García, M. Á. Coagulation-Flocculation Sequential with Fenton or Photo-Fenton Processes as an Alternative for the Industrial Textile Wastewater Treatment. J. Environ. Manage. 2017, 191, 189-197.

[3] Saxena, S.; Raja, A. S. M.; Arputharaj, A. Challenges in Sustainable Wet Processing of Textiles. In Textile Science and Clothing Technology; Springer Singapore: Singapore, 2017; pp 43-79.

[4] Kant, R. Textile Dyeing Industry an Environmental Hazard. Nat. Sci. (Irvine) 2012, 04 (01), 22-26.

[5] Tong, O.; Shao, S.; Zhang, Y.; Chen, Y.; Liu, S. L.; Zhang, S. S. An AHP-Based Water-Conservation and Waste-Reduction Indicator System for Cleaner Production of Textile-Printing Industry in China and Technique Integration. Clean Technol. Environ. Policy 2012, 14 (5), 857-868.

[6] Lin, S. H.; Chen, M. L. Treatment of Textile Wastewater by Chemical Methods for Reuse. Water Res. 1997, 31 (4), 868-876. 
[7] Petek, J.; Glavic, P. An Integral Approach to Waste Minimization in Process Industries. Resour. Conserv. Recycl. 1996, 17 (3), 169-188.

[8] Tang, A. Y. L.; Kan, C. Non-aqueous Dyeing of Cotton Fibre with Reactive Dyes: A Review. Colour. technol. 2020, 136 (3), 214-223.

[9] Ozturk, E.; Koseoglu, H.; Karaboyac1, M.; Yigit, N. O.; Yetis, U.; Kitis, M. Minimization of Water and Chemical Use in a Cotton/Polyester Fabric Dyeing Textile Mill. J. Clean. Prod. 2016, 130, 92-102.

[10] Raja, A. S. M.; Arputharaj, A.; Saxena, S.; Patil, P. G. Water Requirement and Sustainability of Textile Processing Industries. In Water in Textiles and Fashion; Muthu, S. S., Ed.; Elsevier, 2019; pp 155173.

[11] Wang, A.; Xia, L.; Zhou, S.; Guo, H.; Wang, Y.; Xu, W. Solvent Assisted Reactive Dyeing of Cotton with High Exhaustion in the Absence of Salt. J. Clean. Prod. 2020, 267 (122062), 122062.
[12] Tang, A. Y. L.; Lee, C. H.; Wang, Y. M.; Kan, C. W. Dyeing Cotton with Reactive Dyes: A Comparison between Conventional Water-Based and SolventAssisted PEG-Based Reverse Micellar Dyeing Systems. Cellulose 2019, 26 (2), 1399-1408.

[13] Abate, M. T.; Tadesse, M. G. Airflow, Foam, and Supercritical Carbon Dioxide Dyeing Technologies. Innovative and Emerging Technologies for Textile Dyeing and Finishing. Wiley February 2021, pp 137-164. https://doi.org/10.1002/9781119710288.ch5.

[14] Textile Today. Robintex Group Shows Commitment to Environment by Harvesting and Using Rainwater. Com.bd, 2019.

(C)Bangladesh Uni. of Engg. \& Tech. 